\title{
Taking the Socio-Technical Seriously Exploring the Margins for Change in the Traffic and Transport Domain
}

\author{
Boelie Elzen \\ Introduction
}

A well-functioning traffic and transport system is a necessity for an industrialised and complex society. At the same time, the way our traffic and transport system is shaped and functions also causes major societal problems. Emissions of pollutants from vehicles worsen the quality of the air, causing health hazards to humans and other living species. Emissions of $\mathrm{CO}_{2}$ in particular contribute to global warming. The continuously increasing number of vehicles makes it ever more difficult for traffic to proceed smoothly, causing congestion, limiting the accessibility of many destinations, and threatening the livability of cities and other living areas.

These problems have been on the agendas of public authorities since the 1960s. In general, these problems have been split into behavioural and technological problems. Emissions are regarded as a technical problem because the engine technologies and the fuels used discharge hazardous substances. Congestion is primarily a behavioural problem caused by people travelling (too) much and/or choosing an inefficient means of travel.

These problem definitions strongly determine the search for solutions. Emissions are primarily made the problem of the vehicle industry which is requested, or forced by means of legislation, to develop cleaner engines. Congestion is primarily tackled by making an appeal to people's sense of responsibility to society via awareness campaigns that request them to travel less or to make greater use of public transport.

Over the past decade, though, policymakers as well as many others have become increasingly skeptical about the possibilities of influencing people's mobility. At the same time, interest has grown in technical options to tackle congestion problems. There appears to be a shift from the behavioural approach to the technological approach. However, this shift has not remained uncontested. A variety of actors, especially those concerned with the environ- 
ment and the livability of cities, continue to emphasise that only a change of behaviour on the part of travellers can lead to fundamental (or sustainable) solutions for traffic and transport problems.

From an sTs perspective, this distinction between technical and behavioural problems and approaches is not only strange but also counter-productive. s s s research has extensively shown that technical change and societal or behavioural change typically go hand in hand. New technologies rarely just replace existing ones. They also have new characteristics and new qualities that influence the behaviour of users and other relevant actors. The personal computer, for instance, was not developed as a typewriter, but once on the market, it made the typewriter obsolete in just a few years, while at the same time drastically transforming office work.

In this chapter, I propose a strategy aimed at improving the integration of technical and societal/behavioural changes. To that end, I start by presenting a framework of analysis that distinguishes different forms of socio-technical change, depending upon the degree of behavioural change associated with it. Subsequently, I argue that, especially in cases where a considerable degree of behavioural change is desired (in traffic and transport, for example), a learning strategy on the potential of new socio-technical configurations in experiments is crucial. I subsequently present a number of cases to illustrate some potential findings from this kind of strategy. In the final section, I indicate how the approach can be optimised, and I end by concluding that this kind of approach takes the socio-technical nature of innovation much more seriously than current transport policies do, and also has a larger potential to solve transport-related problems.

\section{Different forms of socio-technical change: optimisation versus renewal}

In the past few years, an enormous range of technical options has been developed to tackle societal problems related to traffic and transport. Some of these can be relatively easily fitted into the existing system, while others require an extensive adaptation of the behaviour of producers as well as suppliers and users of transport services. The former type of solutions receive far more attention and are taken far more seriously than the latter.

An "easy-to-fit" option largely means that travellers do not have to change their behaviour, the assumption being that the vast majority will never forego using their private car. For this reason, battery-powered electric vehicles (BEVs) are not considered a serious option since these vehicles only have a 
very limited range on a full battery. This option would require an adaptation of traveller behaviour (e.g., using this vehicle only for short distances and using a train or hired car for occasional long distances). In contrast, fuel cell electric vehicles (FCEVs) do not have this range limitation and are widely considered the "ultimate transport technology" of the future. This view is prevalent despite the fact that, at present, FCEvs are much more expensive than BEVs, the technology is far more complicated and problematic, and infrastructure issues are also more complex. The general assumption is, however, that the technical and economic problems of FCEvs can be solved, whereas the behavioural problems linked to в Evs cannot.

In this chapter, I challenge this neglect of potential behavioural change by highlighting some aspects of the socio-technical nature of innovation processes. To characterise the current situation, I use the notion of a sociotechnical regime (or just "regime": Kemp et al. 2001), in this case, the traffic and transport regime. A regime may incorporate one or several systems in a variable mix, such as the private car system and the public transport system in this particular case.

Regimes are not static but inherently dynamic. Innovation takes place continuously within the regime, but it tends to be conservative with incremental changes. The current problems of the traffic and transport regime, however, require more radical changes to achieve sustainability. In discussing the possibility of achieving this, I distinguish two main routes, namely, "regime optimisation" and "regime renewal", which can be characterised as follows (Elzen et al.1996,1999):

- Regime optimisation relates to innovations that can be fitted in relatively easily. This may concern improving either the public transport system or the car system. Changes are largely technical in nature, requiring little or no adaptation of the traveller.

- Regime renewal relates to attempts to change regime relations more fundamentally through innovations with new characteristics. Examples are new transport modalities (like door-to-door public transport concepts) or new forms of ownership (e.g., car-sharing). A crucial distinction with regime optimisation is that in the case of regime renewal, the behaviour of various actors in relation to various relevant technologies changes considerably; travellers need to do different things to reach their destination.

The distinction is largely a matter of degree. sTs research has convincingly demonstrated that innovation is always socio-technical in nature. Still, for the purposes of this chapter, the distinction is useful since it helps to distinguish the current situation from what is needed. 
Regime optimisation is current practice. This is implied in a self-fulfilling prophecy that assumes that it is futile to try to change people's travel habits and their love of (using) their private car. Innovations that do not fit the current pattern encounter a lot of skepticism and have difficulty in attracting funds. This optimisation approach has succeeded in achieving a drastic reduction of vehicle-polluting emissions but has been very ineffective in tackling congestion. Measures aimed at the latter (such as new infrastructure) afforded merely temporary relief, with problems popping up some time later or elsewhere.

In contrast, regime renewal has a much larger potential for problem-solving, which is not surprising since, in this case, the thinking starts with the type of behaviour that is considered desirable from the societal perspective, whereas regime optimisation takes current travel behaviour as a starting point.

A variety of innovations that would fit a renewal perspective have been proposed. The problem with such innovations is that they do not fit the current regime, either on technical grounds (e.g., because of the lack of appropriate infrastructures) or on societal/behavioural grounds ("I am not going to share my car with others"). Small-scale introduction can occasionally be realised, but innovation can only give substantial relief when applied on a large scale. Such upscaling to realise regime renewal requires interaction between a variety of new elements. Thus, the problem is not so much the development of new technologies but the tuning and the societal embedding of them.

\section{Experiments as a breeding ground for new socio-technical configurations}

Regime renewal in itself is nothing new. The current traffic and transport regime, for instance, differs drastically from that of 50 years ago when cars had a minority share of traffic. The question is whether it is possible to induce regime renewal and guide it in a direction with far fewer societal problems. To answer that question in full is beyond the scope of this chapter, but I shall provide a part of the answer by emphasising the need to learn via socio-technical experiments.

Regime renewal is difficult to realise because a large set of interrelated barriers impede radical change. These may include:

- technological factors

- government policy 
- cultural and psychological factors

- market factors

- production factors

- infrastructure and maintenance

- the possible undesirable societal and environmental effects of new technologies.

Despite these barriers, history shows that radical change may still take place because new technologies, although not (yet) ready or able to compete with existing technologies, are initially developed and experimented with in "protected spaces". The new technology is protected by various actors who believe in its long-term prospects and who are willing to invest time, money, and effort in "making it work", in both technological and social terms. Such protected spaces are called "technological niches" or just "niches" (Kemp et al. 2001). These niches are experimental situations characterised by a "learning by doing" approach. By trying out a variety of changes, an attempt is made to lower or overcome the diverse obstacles.

Across the world, experiments are currently being performed utilising a wide variety of transport innovations, in pilot or demonstration projects. All these experiments involving a specific technology (such as electric vehicles) collectively make up a technological niche. A major problem is that many such projects within the niche are once-only affairs with little mutual exchange of information. A deliberate strategy can then be followed to learn across these projects within a niche and, as a next step, to use this knowledge to define further experiments attempting to integrate findings. This requires the co-ordination of the activities of a wide range of actors. The (policy) approach targeting this co-ordination is called strategic niche management, $\mathrm{sNM}$ (Weber et al. 1999; Hoogma et al. 2001). In the sNM approach, the general objective of experiments is to learn how new technologies and their societal embedding can be mutually attuned.

Looking at past and ongoing experiments (usually called "pilot" or "demonstration projects"), the vast majority of these have a strong bias for technical (and economic) factors, and neglect the behavioural side. This, however, side-steps the major problem since one of the most "wasteful" characteristics of the current regime is the individual use of a single vehicle from door-to-door for any kind of purpose. The challenge, therefore, is to organise learning in experiments in such a way that it teaches something about the potential for behavioural change.

To illustrate what this may render, I shall describe some experiments with transport innovations, focussing on what they may teach with regard to op- 
tions for renewing the traffic and transport regime. These examples are not mainstream, in the sense that they do not easily fit the current regime, and most transport experts find them rather uninteresting. For the purpose of this chapter's argument, however, they are all the more interesting since their technical drawbacks induced innovative thinking on the behavioural side.

\section{Introduction to the cases}

I shall explore this further through the analysis of three recent experiments with electric vehicles (Evs). Electric vehicles fit into the current traffic and transport regime very poorly. Energy is stored in large batteries that weigh several hundred kilograms. Despite their large mass and volume, they give the vehicle a range of only 50-100 km, after which the battery needs to be recharged. In most cases, this takes 6-8 hours, although with expensive equipment this can be speeded up to approximately half an hour. The large batteries are expensive, costing several thousand euros for a typical vehicle, and may have to be replaced one or more times during the vehicle's lifetime, depending on the battery technology. This long list of negatives has made skeptics argue that Evs have been, are, and always will be the technology of the future. So why bother?

Their major advantage is that they produce no polluting emissions. That is why they are also referred to as "zero-emission vehicles" (zevs). Emissions do take place at the power plant producing the electricity, but there they are less harmful to humans than the emissions of vehicles in the cities. Even taking power plant emissions into account, the overall emission from evs can easily be $50-80 \%$ better than that of conventional vehicles, in part depending on the type of power plant.

This low level of polluting emissions stimulated the US State of California to pass legislation in 1990 decreeing that, by $2003,10 \%$ of vehicle sales from the major car manufacturers should be zevs. ${ }^{2}$ All through the 199os, the major car manufacturers fought this requirement on the ground that Evs were more expensive and performed a lot worse than conventional vehicles, and that they could not possibly find customers for them. Implicitly, they thus argued that evs did not fit the then current traffic and transport regimes.

Interestingly, though, this "technical drawback" of evs led to innovative thinking on user behaviour in connection with these vehicles. Various experiments were set up in which Evs were used in a way different to conventional vehicles. I briefly discuss three of these projects below, notably a 6-year project with "lightweight electric vehicles" in Mendrisio, Switzerland, an experi- 
ment with a "self-service" EV short-term rental system near Paris, and a comparable but less ambitious scheme in Turin, Italy. I have studied these cases in depth, along with many others, within the framework of an EU-funded international co-operative project under the name of utopia. ${ }^{3}$ The results of these analyses can be found in Zwaneveld et al. (2000) and Ricci et al. (2000). The brief descriptions below are partly based on these sources, partly on other sources indicated.

\section{Case 1: Mendrisio - LEV market stimulation ${ }^{4}$ \\ Experimental set-up}

In the early 1990s, the Swiss Federal Ministry of Energy (BEW - Bundes Energie Wirtschaft) launched a program called "Energy 2000" to promote measures to stabilise the consumption of fossil fuels and $\mathrm{CO}_{2}$ emissions as well as to support renewable energy sources until the year 2000. To operationalise this program, B EW evaluated the potential of the lightweight electric vehicles (LEVs) developed by various small innovators and concluded that such vehicles were very energy-efficient and would cause far lower polluting emissions than conventional cars.

To realise this promise, LEvs would have to be used on a large scale. A vision was developed foreseeing a LEV park of 200,000 vehicles by the year 2010 , i.e., $8 \%$ of the total car fleet. As a medium-term goal, the energy consumption of these vehicles should be equivalent to 1 to 1.5 liters of gasoline per $100 \mathrm{~km}$, roughly five times as energy-efficient as conventional cars.

After considering various alternatives, it was decided to realise a large-scale experiment in one community plus a number of smaller experiments in socalled "partner communities". One of the main objectives would be to explore the effects of a range of promotional measures. Thus, the "Großversuch mit Leicht-Elektromobilen" (large-scale experiment with lightweight electric vehicles; in short "Großversuch") was defined (Muntwyler 1997).

In December 1994, the community of Mendrisio, in the southeastern, Italian-speaking canton of Switzerland, was chosen to host the large-scale experiment. In Mendrisio, the LEv target of $8 \%$ of the national car fleet by 2010 would already be realised in 2001. The experiment was to start in 1995 and be divided into 3 two-year project stages. Each project stage would be evaluated on the basis of the adjustments to be made. This would allow for flexibility in the project plus a safeguard that it could be stopped at an earlier point if the results were too meager.

Over 50 promotional measures were identified for the experiment. Most 
noticeably, the purchase price for LEvs would be subsidised by $30-50 \%$, depending on vehicle performance. Lightweight vehicles are not defined by their weight but by their energy efficiency (which is strongly correlated). Electrically assisted bicycles and motorcycles are also subsidised by $50 \%$, while all other types of $\mathrm{EV}$ are subsidised to a maximum of $30 \%$.

The total budget for the Großversuch was 33 million SFR, just over $€ 20$ million. About $65 \%$ of the budget was used to subsidise the purchase of vehicles, while close to $10 \%$ was for the set-up of an infrastructure. The remainder was reserved for project management and concomitant research. Firms wanting to sell vehicles in the experiment had to lower their sales price by about $10 \%$. Furthermore, the canton and the community guaranteed $17 \%$ (Schwegler et al. 1994).

The Großversuch was not only a pilot and demonstration project, but also a research project. It was considered to be an unconventional, large-scale practical test on a scale of 1:1 (Schwegler et al. 1994). An intensive research program was conducted to analyse the effects of specific promotion measures.

\section{Results}

In mid-1999, four years into the project, the number of vehicles sold lagged somewhat behind target. In the following two years, sales went up considerably, and by 30 June 2001 the number of Levs sold amounted to 395,45 more than the target of 350 (Meier-Eisernmann et al. 2001).

A more important goal was to demonstrate the usefulness of LeVs in everyday life and to learn which support measures would help LEvs on their way toward market success. Most of the project participants were satisfied with their vehicles, even though the range of the vehicles was often smaller than promised by the dealers. The reliability of the vehicles appeared to be good, and the vehicle costs were considered fair, which implies that the official price of the vehicles (without federal subsidies) was still too high to introduce the vehicles in an open market.

Concerning support measures, three two-year stages for introducing LEVS on to the market were distinguished. In the first stage, people's interest in LEVs was evoked by giving them the possibility to test the new technology. In the second stage, the financial disadvantages were reduced, and an infrastructure was realised. Finally, in the third stage, a good after-sales service was set up, and experts such as local garage owners were further educated.

LEV s are a good example of how new attributes from new technologies can induce people to behave differently to what they themselves might expect. For 
instance, ex ante surveys indicated that LEV users across Switzerland evaluated the new option of individual mobility as an addition to their existing options. Since most household travel involves short trips, the LEv became the most frequently used vehicle. For a variety of reasons (e.g., quietness, environmental friendliness, novelty) people started to prefer the $\mathrm{EV}$ to their conventional vehicle, and they tried to avoid using the latter by planning trips more carefully. They tended to avoid long and energy-intensive trips and always sought the shortest way to reach a certain destination. Thus, they surprised even themselves, as they tried to make as many trips as possible by LEV and changed their behaviour accordingly. Most LEV users were convinced that the LEv technology was sensible and future-oriented and should be actively supported.

\section{Evaluation}

The results of the Mendrisio experiment can be evaluated in various ways. One of the most obvious success criteria could be the number of vehicles sold. The set target was reached, but this teaches us little about the possibilities of and the barriers to the introduction of innovative transportation schemes. More important are the lessons involving users' mobility patterns, the environmental aspects, and the effectiveness of political support measures. The organisers of the Mendrisio project obviously shared this view, given the extensive evaluation scheme on all of these aspects. Most of the objectives were achieved in this respect.

The original goals of the experiment went beyond simply being a test project for electric vehicles. The overarching goal was to demonstrate integrated, sustainable forms of mobility in which LEvs would play an essential role. The achievement of this goal not only required a careful combination of promotional measures and technological improvements of the vehicles but also learning processes on the part of the consumers.

More important than the number of Evs sold were the insights gained in processes that support the dissemination of the technology. Insights have been gained on:

- the importance of specific promotional measures. These experiences will prepare the ground for a nationwide introduction of LEVs in individual communities.

- technological questions related to the performance and environmental characteristics of the vehicles in everyday use. 
The large-scale experiment with LEvs in Switzerland may be seen as a paradigmatic example of "Strategic Niche Management" (see above). Policymakers take up the initiatives of individual citizens and small enterprises and try to support the dissemination process of the technology in a non-authoritarian way. Actor-learning, networking, and expectation management are active parts of the project set-up. The framework of the experiment is flexible, and communication and monitoring receive major attention.

A major point yet to be resolved, however, which will be analysed in a follow-up project, is the question of the relationship between the experiment and the real market. Should the experiment be a testing field, a kind of laboratory in which components of a system are tested, or is the experiment a kind of a simulation tool in which "critical paths" have to be identified? In the former case, the problem field consists of a number of "valves and regulators" which have to be fine-tuned to achieve results. In the latter case, qualitatively different routes may be taken, and the experiment has to identify these routes and to determine the trade-offs they imply.

Although the LEV market share is virtually negligible in the overall Swiss mobility spectrum, there are interesting indications that this new type of vehicle may change mobility patterns. Although the LEv technology relies on automobile technology and LEvs are located "at the doorstep" (unlike, for instance, car-sharing projects), users have to adapt their mobility patterns to this new technology. They must learn how far they can drive on a battery charge and how long it takes to recharge the batteries. Because of these limitations, they have to make a conscious decision whether or not the LEV is suited for a certain trip. It makes people more reflective on their travel needs and more open towards various options to satisfy those needs. In short, their thinking becomes less automobile-centred.

\section{Case 2: Praxitèle - An advanced Ev self-service system ${ }^{5}$}

\section{Experimental set-up}

The initiative for Praxitèle was taken by CGFTE, a French public transport company operating nationally. In 1989, CG FT E organised a discussion meeting with passengers seeking to identify "the ideal transport concept". Among several alternatives, a concept based on self-service rental cars was seen as a strong option. It was believed that this kind of system could combine the advantages of cars with the advantages of public transport. A practical set-up should guarantee a parking place for the car user, be easy to operate, and use non-polluting vehicles. 
After several (feasibility) studies and interaction with other French companies and ministries, this idea evolved into the Praxitèle concept. Praxitèle is a self-service EV rental system. It is based on a fleet of small vehicles - the Praxicars which are located in specific areas called the Praxiparcs. The whole system is supervised with the help of a central computer, the Praxicentre.

The experiment, the first of its kind, started in October 1997 in the "new town" of Saint-Quentin-en-Yvelines, an outlying Paris suburb, about $15 \mathrm{~km}$ from the centre. It has 140,000 inhabitants and two expanding industrial zones and is considered the second most important business area in the westParis region. It is linked to Paris by an extensive motorway system as well as a fast urban train line (RER).

Fifty Evs, electric Renault Clios with a 70-km range, were available to the public. In the long term, a novel vehicle specifically adapted to city use (a small, lightweight energy-efficient $\mathrm{EV}$ ) is also being developed. The vehicles were eventually located in 15 different stations at strategic places in SaintQuentin-en-Yvelines like railway and bus stations, shopping and business centres, hospitals, etc. A car could be taken any time from any of the stations, used freely as if it were a private car, and then returned to any of the stations. It could be used by several drivers during a day, which reduced the required parking space in the city centre. Drivers only had to have a valid driver's license and register as a member the first time they used the system. From then on, members could use the car as they liked, much as they would their own private vehicle, getting in by means of a bankcard-like "Praxicard". Each client was automatically billed at the end of the month for the time s/he had actually used the service.

The fleet of Praxicars was controlled by the Praxicentre, which informed users about the nearest available vehicle via Praxi terminals or phone. It used new telecommunications and localisation systems that were considered necessary for the success of the system, since earlier experiments with self-service cars had failed due to the lack of efficient fleet management. Each vehicle was equipped with a GPS-based positioning system allowing the vehicle to locate itself with a precision of about 30 meters. The Praxicentre also handled reservations and transfers to other types of transport (train, bus, taxi).

The project partners were CGEA Transport (CGFTE's parent company), Renault, EDF, Dassault Electronique (now Thomson csF Detexis), and the Municipality of Saint-Quentin-en-Yvelines. Especially the participation by Dassault is interesting, as it has no tradition in the transport business. Dassault primarily produced military electronics, but with the collapse of the market for military equipment, it started to look for new markets in which to diversify from early 1990 on onwards. Companies in this kind of position tend 
to be more open to innovative approaches in a new field where they face less established competition.

The project budget was FF 30 million, just over $€ 4.5$ million, of which $50 \%$ was paid by the partners and the remaining $50 \%$ by the Ministry of Transport, other French agencies, and the European Commission. The broad objective of the Praxitèle experiment in Saint-Quentin-en-Yvelines was to demonstrate the usefulness and economic feasibility of an individual public transport system based on a centrally managed fleet of small electric vehicles.

\section{Results}

The experimental phase of Praxitèle officially started on 16 October 1997 and was concluded in early 2000. From the evaluations, it appeared that a significant number of people had used the service. In May 1998, 400 members had registered, a number that was to double one year later. In the one-and-a-half years since the start of the experiment they had made 25,000 trips, covering an average distance of 8 kilometers in 15 minutes. In April and May 1999, the average use was about 500 trips a week, i.e., about one-and-a-half trips per car per day.

Users indicated they were very satisfied with the service. A growing group of clients became regular users as they learned how to use the system in reallife practice. They changed their transport behaviour, especially when they had no regular access to a private car. Users particularly appreciated the freedom, the ease of use of the self-service system, and the availability of cars without worries about maintenance. They valued the fact that the cars were electric, as an expression of their environmental concerns.

The main problems were related to the experimental and innovative features of the service. Continuous adaptations were made during the experiment to solve the technical problems that were encountered. Concerning economic aspects, it was evident from the beginning that the scheme would not be economically feasible. The costs of Evs, because they were not made as a mass product, were far too high, while an economic break-even point was not expected with a scheme with less than a few hundred vehicles. At the very least, the experiment has proven that there is a substantial demand for this kind of service. How this demand can be satisfied in a cost-effective way is as yet unclear, as detailed economic evaluations have not yet been made.

Initially, it was feared that the system would compete directly with taxis, and there was even a threat of resistance from taxi driver unions. In practice, taxis have not experienced a loss of clientele. The self-service system was a complement to existing public transport systems that may have taken away 
some customers from taxis but may also have increased their client base by creating demand for a taxi in cases where there were no self-service vehicles available at a specific station when needed.

The managers of the project were satisfied that the technical feasibility of the system had been proven and that more detailed results should help define the conditions for successful implementation of the service. Larger-scale projects are being considered for other sites, and a project has been proposed for Paris with some 2,00o cars. In the longer term, an operator should be able to offer cities and public transport authorities a service based on this type of self-service system. The Praxitèle experiment suggests that there is a place for a self-service car system in urban transport.

\section{Evaluation}

Within the framework of an EU-funded project on strategic niche management, interviews were held with a variety of people who worked on the Praxitèle project (public bodies and partners in the experiment). In these interviews, two main issues emerged: the funding and the technical complexity of the experiment (Simon 1998).

One crucial aspect of the Praxitèle project is the large number of technological innovations incorporated in the system, including:

- the non-contact smart card that offers easy access to the cars and facilitates fare collection;

- the automatic connection with the inductive charger;

- electric vehicles;

- real-time communication between the vehicles and the management centre; on-board electronics to control the vehicle, assist the driver, and calculate the trip cost;

- mathematical models to optimise the redistribution of cars among Praxicars, and the recharging process of electric vehicles; and

- multimedia terminals installed in the Praxiparcs to assist the users, e.g., to call a vehicle when required.

Many of these innovations were not standard technology for most users of the Praxitèle system or its operators. It was quite risky to include so many innovative technologies in a transport system that was itself a radical innovation as a transport concept. The increased risk of technical failure could have had a negative impact on the perception of users who could confuse the usefulness of the concept with the way it functioned. This also raised more problems in assessing user satisfaction and the functioning of the system. 
To avoid these risks, a less ambitious set-up could have been chosen, by drawing upon certain car-sharing systems that incorporated very simple technologies and operated quite well, for instance. However, this might have invoked other problems. For example, if conventional cars had been chosen rather than Evs, there might have been a problem in finding a suitable location as most municipalities were primarily interested in transport projects with "clean" vehicles.

The initiators of the project were well aware that it was risky because it involved a wide variety of new elements: a new transport concept, various new technologies, an unusual combination of network partners. Several partners were among the largest firms in France, yet they were not willing to invest large sums because of these risks. As a consequence, the Praxitèle consortium looked intensively for public support. Also in this strategy, the project risk proved to be a major hurdle that delayed the experiment for almost two years. The industrial partners wanted public authorities to commit themselves to the project because the project would be so innovative (and, consequently, risky) while public authorities were also reluctant to give major support for the same reason.

Eventually, the project was funded in spite of much opposition. There were technical problems, but the service did work well enough to allow an exploration of the concept in a practical situation. It appeared that a substantial number of users valued it as a useful and environmentally friendly complement to public transport. These drivers form a very small minority in relation to the total number of car users, but the results legitimise designing a largerscale follow-on project to explore how this kind of concept can be transformed into a service useful to many.

\section{Case 3: Elettra Park - the Turin automatic electric car rental ${ }^{6}$}

\section{Experimentalset-up}

The quality of the air in the city of Turin in the early 1990s was considered to be rather poor. A substantial part of this was attributed to extensive car use. Noise was also considered an important nuisance. The Turin city authorities felt they had a responsibility to reduce $\mathrm{CO}_{2}$ emissions and the associated greenhouse effect. To tackle these problems, the city supported a project with a number of Evs that were made available at rental stations on the periphery of the city where people had arrived by other means. They could rent the EV for a limited period to serve their needs in the city, bring it back to the station, after which it would be available again for use by others. To make this type of scheme functional, it had to be transparent and easy to use. 
The experiment, named Elettra Park, was started in 1996 as a joint venture between the Turin City Council, ATM (Public Transport Company), AEm (Electricity Company) and Fiat. Elettra Park consisted of 22 electric Fiat Pandas that could be rented automatically from a public parking area. The parking lot was on the edge of the city centre, was easily accessible by public transport, and had separate sections for Evs and conventional vehicles. The Evs could be used only within the urban area, from 7.00 a.m. to 10.30 p.m. every day of the week. The cars had room for two passengers as the battery took up the entire rear seat room. The battery allowed an urban range of about 50-70 $\mathrm{km}$ and then took 8 hours to recharge.

Customers first had to sign a contract at the permanently staffed office and pay a deposit. The customer then received a chipcard that stored a prepaid budget. At the parking lot, the customer could use her/his card to open the door of an $\mathrm{EV}$ and subsequently use it. After use, the vehicle had to be returned and parked in any of the spaces designated for Evs. The minimum rental fee was 3500 lira (approx. $€ 1.8$ ) for up to one hour of use. After this period, an additional fee was charged per minute at a rate of 3500 lira for the second hour and 5000 lira for each additional hour. The fee included rent, electricity, third-party liability and motor hull insurance, and parking fees for the $\mathrm{EV}$ in the city as well as for the customer's own vehicle in the designated area in Elettra Park while s/he was using the Panda Elettra.

The project consisted of two stages: the first stage, from 23 September 1996 until the end of 1997, was to test the "basic features" of the system, and a second stage that went until the end of 1999 with a new cost and regulation structure. Turin City Council announced the availability of the cars through a variety of means, such as advertising on billboards, in public offices, at the university, etc.

The total budget was 2 billion Italian lira (about $€_{1}$ million). The funds came from the City Council, an institutional environmental project, and Fiat. The main learning goal of the project was to test the users' acceptance of a new individual and public transport system. Data on the system's performance were continuously collected by monitoring the technical operation as well as customer behaviour and feedback. The latter info was collected through surveys and telephone interviews, and all data were processed by a local transport research centre, Csst.

\section{Results}

During the project, information was collected on numbers of customers, patterns of use, behavioural aspects, and opinions on the initiative. In the first 
stage of the experiment, until 1 January 1998, almost 2000 cards had been sold to users. Peak sales occurred in the first few weeks, with 800 cards sold in the first month, dropping to an average of around 10 new customers a week after one year. In total, during the first stage, close to 12,000 trips were made covering over $200,000 \mathrm{~km}$. This corresponded to an average of 27 trips a day. On average, each vehicle was rented for about three hours a day, in which it was driven for about 1.2 hours. This rate of use was about $50 \%$ higher than that of the average privately owned conventional vehicle in Turin.

To learn about possible changes in overall mobility patterns, an analysis was made of where the users came from and of the transport means used to arrive at Elettra Park. The majority of users lived nearby and walked to the parking area. About one quarter of them used public transport, while a small minority exchanged their own conventional vehicle for an $\mathrm{EV}$ at the transfer point. The vehicles were mostly used for shopping and running errands, while a minority of the trips were for work purposes. The users indicated the Elettra Park scheme had two attractive features, namely, that parking was free and that the $\mathrm{Ev}$, because of its zero-polluting emissions, was allowed to drive in areas closed to most other traffic.

Overall user satisfaction was decidedly positive. Over $50 \%$ of the users stated that the system was good, while $22 \%$ judged it as excellent, and none of those interviewed gave an overall negative judgement. The operations involving the borrowing and returning of a vehicle, which appeared to be complicated in the design phases, were judged to be easy; there were no problems with the management of the card, and the fees were considered fair.

The most serious points of criticism were the opening hours and waiting times. Over one-quarter of the customers felt that the system should be open longer during of the day. Furthermore, right at the outset, it appeared that the demand was higher than the availability of vehicles. Because of this, some people abandoned the system, but most liked it enough to wait for an EV to return. Also, the more frequent users got used to the system as time went by, and learned when the chances of obtaining a car were the highest.

\section{Evaluation}

As an experiment, Elettra Park has been in operation for several years, and as a transport service, it has become a part of the living habits of a good number of Turin residents. It is an interesting case because it looks at the technical as well as the behavioural aspects of mobility. It has rendered knowledge on the potential of a public transport service using personal vehicles and, in some cases, on how to combine this service with the use of a privately owned conventional vehicle. 
The experiment has yielded several important insights, such as:

- it has demonstrated the feasibility of a system of instant rental of vehicles operating under conditions of complete autonomy;

- it has demonstrated a significant interest in a transport system with minimum environmental impact and has created, in particular, renewed interest in electric vehicles;

- it has been accepted by a large (perhaps too numerous) group of users who had no difficulty in subscribing to and using the service;

- it has shown that many urban trips, for various reasons, can be made with vehicles with limited autonomy;

- it has found its specific market niches of optimum use within the context of the need for mobility in city centres.

The project also demonstrated the need to improve specific features of the scheme, such as the correct size of the car fleet to guarantee an efficient service. A more technical facet, already anticipated, was the need to reduce the recharge requirement in order to increase a vehicle's daily autonomy. Towards the end of the project, on the basis of the initial findings, the Turin City Council developed plans to create four other transfer points in the city for an interchange between conventional and electric cars.

The overall experience was quite satisfactory, and there were only minor technical problems. The technical aspects of the electric Panda and its recharging infrastructure were judged quite positively. In general, user satisfaction was also very positive. They confirmed that electric cars provided a comfortable mode of transport and that the set of privileges granted to stimulate their use (free parking, the possibility of driving inside limited access zones) made it interesting and attractive.

\section{Relevance of empirical findings for sustainable mobility}

In the common view, battery-powered electric vehicles will not play a very serious role in the greater traffic and transport regime. At best, they are considered an intermediary step towards further innovations like hybrid electric vehicles (that combine an internal combustion engine with an electric drive) or fuel cell electric vehicles. This bias in thinking, however, is caused by seeing EVs as a mere substitute for conventional vehicles. Interestingly, these "technical drawbacks" have led various actors not to think in terms of improving EVs but in terms of changing the behaviour of travellers. Thus, technical 
change is used as a lever to evoke behavioural change.

The Praxitèle and Elettra Park projects clearly feature a vision of a new transport concept. They can be considered as specific examples of novel individualised public transport systems. Evs are not just seen as a vehicle to replace the existing car but as a new transport mode to be used in conjunction with other modes. Although less explicitly, this is also reflected in the Mendrisio experiment, e.g., by offering a railway pass to $\mathrm{EV}$ owners.

In all of these projects, users were fairly positive about the vehicles and the set-up. The users of the Elettra Park confirmed that electric cars provided a comfortable mode of transport and that the set of privileges granted to stimulate their use (free parking; possibility to move into limited access zones) was interesting and made it attractive to use a modal chain. The technical aspects of the electrical Panda and its recharging infrastructure were also judged quite positively. Praxitèle has also stimulated a change in traveller behaviour towards intermodality. At the very least the experiment has proven there is a substantial demand for such a service. ${ }^{7}$

What do these findings imply for sustainable mobility? It should be acknowledged that it is too soon to make firm claims about the wider potential of such schemes. Still, it can be illuminating to speculate a little on the possibilities of these concepts stimulating a transformation of regime. Experiences with pioneer users and the users within the Mendrisio experiment suggest a role for LEvs in a future, more environmentally benign mobility system. Most LEV users initially bought their LEV as a second car. Subsequently, however, the first car declined in importance, and the attitude towards individual mobility became increasingly open-minded and less "automobile centred". As LEVS are able to cover short distances and are best suited for regular trips, which are easy to plan, they would be an ideal complement to car-sharing (to satisfy the occasional need for a long-distance ride) or public transport.

Elettra Park and, especially, Praxitèle have demonstrated that these schemes provide a useful link in an intermodal mobility chain for various users. In various national and Eu policy plans, functional intermodal chains are seen as a major promise to reduce the dominance of the private car. This would be a very environmentally friendly and energy-efficient scheme, especially if these schemes included LEVs. This would thus provide an important step towards sustainability on several dimensions.

Thus, in contrast to the common view presented at the start of this section, these experiments have rendered positive results on the potential of Evs as part of a sustainable mobility regime. They do so because they have not taken current travel behaviour as a starting point but have exploited the "technical drawbacks" of Evs to induce a change of behaviour. 


\section{Inducing and guiding socio-technical change}

The previous section raises the question of the wider relevance of these results for inducing change towards sustainable mobility. Thus, the first issue is to optimise learning in experiments so that it renders useful information on the potential of a combined technical and social/behavioural change. The second issue is to use this knowledge to stimulate the wider uptake of new options, which implies a change in the roles of various actors.

\section{Learning in experiments}

A wide variety of alternative transport options have been tested in many countries around the world. They include new propulsion technologies (electric, hybrid, natural gas, bio-fuels), new vehicle types (electric and power-assisted bicycles, city-cars), new transport concepts (people movers, ondemand services, personal public transport), new ownership configurations (car-sharing). The findings of these projects were usually ambiguous, often indicating some promising features as well as barriers to practical use. ${ }^{8}$ This variety of options is called the "portfolio of promises" (Elzen et al. 2001, 186191). A promise in this case means that an option has certain characteristics that, when fully exploited, would offer a far more sustainable solution to (some of) our traffic and transport problems than current "mainstream developments". Each of these options, however, also has problems that prevent it from being used on a large scale.

In such a situation, it is not wise to cut the knot now and focus only on a few of them. It is important to first explore the potential of a variety of options further and to combine the findings of different experiments in order to be able to assess the potential under different circumstances. Because the results of past projects were ambiguous, it is important to design proper projects to learn more about the potential and feasibility of various options, the world in which they have to function, and the measures that need to be taken to mutually adjust the technologies and the social environment in which they have to be produced and used.

Looking at the learning processes of past and currently ongoing experiments, the subject of learning is usually far too narrow. Most experiments are either seen as the final step towards implementation, even when there are many unknown issues, or they are a once-only affair without a clear vision on how to use the results for the next steps. Because of the focus on direct implementation, most projects also have a strong emphasis on the economic aspects. However, this makes little sense with regard to more radical innova- 
tions since transport concepts, user behaviour, and vehicle characteristics will only become clear in a longer iterative process of socio-technical change. The optimal vehicle in a Praxitèle-like scheme, for instance, is not the heavy type of EV used in the experiment but, more likely, a very small, relatively lightweight vehicle with a rather limited range that could be much cheaper than current vehicles on the market. Assessing economic aspects on the basis of the current experiment is therefore highly unrealistic.

In terms of the subject of this chapter, current experiments have a bias towards technical (and economic) factors, not acknowledging that innovation is a co-production process in which the social and the technical facets are both subject to change. However, this is a missed opportunity since, in some cases, the behavioural side may provide the largest potential to achieve societal goals.

Another major flaw in current practice is that experiences from different projects are not combined. Individual projects hardly ever build further upon the experiences gained elsewhere, and results are not made widely available. Evaluation reports from different projects use widely varying evaluation methodologies attuned to local interests, making it very difficult to draw generalised conclusions by comparison. This creates a barrier for a process of collective and accumulative learning.

This would be much improved if at least some of these evaluations were to follow some standard guidelines. These could easily be enforced by the Eu or national agencies that usually sponsor such projects. From their position of power or authority, these organisations could set minimum requirements for the evaluation process. As stated above, these evaluation guidelines should address technical as well as social/behavioural issues in order to exploit the socio-technical co-construction potential to the full. ${ }^{9}$

\section{From niche explorations to regime change}

It is one thing to develop and explore new socio-technical configurations in a niche, but quite another to implement them on a scale sufficiently large to change the existing regime. The vast majority of transportation experts and policy makers argue that such "niche experiences" are largely irrelevant since it is futile to challenge the dominance of the car. They argue that there is no alternative that has all the attractions and functionalities of a car.

However, transformation processes in the past have indicated that innovations hardly ever attract large groups of users immediately. Especially the more radical innovations are initially only used by a relatively small group of "early adopters" (Rogers 1983). In some cases they may gradually attract larger 
groups, either because of new features that new groups of users find attractive or because of increasing problems in the existing regime (or a combination of both). Especially in the case of radical innovations that do not fit readily into existing user patterns, we see a co-production process par excellence, i.e., there is a continuous change on the technical as well as the behavioural side: new user constituencies have new requirements, leading to some technical change that may then attract further user groups, etc.

In this respect, a first hurdle in the above-described experiments has already been taken, which is to demonstrate that a group of "early adopters" can be found, illustrating that there is more room for change in traveller behaviour than is commonly assumed. An interesting next step would be to take a closer look at these first users and to investigate what stimulated them to change their behaviour and, from this, to infer the obstacles and the opportunities with regard to attracting wider groups of users. On the basis of this type of analysis, various hypotheses might be developed, to be tested in further experiments. After further learning has indicated that a "working" socio-technical configuration can be developed, an attempt can be made to scale up by means of regular market processes or via government stimulation or regulation.

This, of course, is easier said than done. We face a whole new set of problems, since what we need to deal with is not just the sale of a new technology but the development of a new socio-technical configuration on a large scale, which requires a whole set of changes, such as new vehicles, new services, new infrastructures, new user patterns, new regulations, etc.

A starting point on how to achieve this could be to look at the policy instruments that have been used in the past to tackle traffic and transport problems, including:

- regulation (e.g., safety and traffic rules, emission standards);

- financial instruments (taxes and subsidies);

- infrastructure provision.

These instruments have been used with some success, especially to curb polluting emission, but they have proved rather ineffective in stimulating behavioural change. In the 1990s, it was increasingly acknowledged that the latter would require, among others, more open and participatory policy making processes. But the way in which this could actually be implemented, and the way a balance could be struck between public participation and political "knot-cutting" remains an open question and subject to a lot of ongoing debate and research. ${ }^{10}$ To even capture the highlights of that debate would be beyond the scope of this chapter. 
Nonetheless, the point can be made that whatever the nature of the process to stimulate wider use of specific options, the quality of the outcome increases when more options are available and have demonstrated their strong and weak points in experimental settings. This is especially true of options that demonstrate the possibility of behavioural change, since this kind of change is seen both as a necessity and an impossibility in the present situation.

\section{Changing actor roles}

This impossibility is partly based on the observation that different types of actors are strongly committed to the current regime, making it unattractive, difficult or unprofitable for them to change. A closer look, however, reveals that these networks are not homogeneous. Some actors start changing their visions and roles in a way that could give new options a better chance. Let me give a few examples.

The larger car manufacturers, in particular, have become aware that the popularity of the car might mean that it is digging its own grave, particularly in urban areas. At least some of them have shown an explicit interest in longer-term visions that attempt to combine the use of personal vehicles with mass transit systems. The participation of Fiat and Peugeot in the two experiments described is a clear indication of this. In both cases, their emphasis is more on the conceptual aspects of the set-up than on the sale of the vehicles used. These industries seem to be well aware that the technical characteristics of an $\mathrm{EV}$ call for changes in behaviour that, in turn, will affect the design of an $\mathrm{EV}$ to match that new form of behaviour to an optimum degree. They realise that a mass-produced Ev has yet to be defined and that such experiments could help them to do so. This is a rather uncommon type of openness towards learning on the part of the car industry, which, however, could be an important asset in the long term.

Additional support may come from industries that are facing problems in their traditional markets and are therefore looking for diversification. The participation of Dassault in the Praxitèle experiment is a clear case in point. EVs thus stimulate new thinking about transportation, which also stimulates new actors to become part of transportation networks.

Another important actor in the traffic and transport regime is the transport providers. They face enormous challenges as, on the one hand, they are urged to increase the quality of their services to compete better with the private car while, on the other hand, the tendency towards liberalisation over the past decade has forced them to work more cost-effectively, which puts a strain on quality. This strain makes some of them more open towards innova- 
tive concepts that are not just a repeat of the same old notions. This is clearly the case with the transport operators involved in Elettra Park and Praxitèle. Their participation is important in order to increase the chances that the schemes will be used in practice if experimental results actually justify this. There is a lack of transport operators in the Mendrisio experiment, making it unlikely that evs will ever be used in or in combination with public transport schemes. It is striking, for instance, that the rail passes offered with the Evs in Mendrisio are hardly used.

Users have traditionally played a rather passive role in transport innovation. Innovations were shaped by industry and marketed partially in accordance with relevant government regulations. All that users could do was either accept or reject an innovation that was shaped elsewhere. In the three experiments discussed, however, users played a much more active role, and their views on the changes necessary to improve functionality and attractiveness were taken into account. In the Praxitèle case, user opinions even helped to identify this as a promising concept that was subsequently developed into an experiment. In Switzerland, pioneer users defined the concept of a lightweight Ev. Obviously, the active involvement of users can help to define innovations that come close to their own needs. This innovative power of users, which is more radical than that coming from technology developers in many cases, can be an important asset to tackle the problems of traffic and transport.

The role of various government bodies is also changing. Many local governments in particular are fed up with the problems of massive car use. They are more open towards experimenting with radical solutions, contrary to the skeptical opinions of experts, and they are increasingly taking more drastic measures, such as closing off parts of the city for cars and only admitting "clean" vehicles. National and Eu authorities are also rethinking their roles. They are displaying greater openness towards unconventional new options, although when new policies are eventually implemented, they do tend to confirm the existing situation of car dominance. One of the major reasons for this is that they believe that there are no serious alternatives "for the masses".

As was argued in the preceding section, this is partly due to the fact that lessons from a wide variety of experiments with alternatives are not combined to generate a cumulative learning process. It was also indicated how governments or their agencies themselves could fill this gap by formulating specific evaluation requirements for experiments with transport innovations. Most importantly, such evaluations should address technical as well as behavioural aspects, to acknowledge and exploit the socio-technical nature of innovation. 


\section{Conclusion}

To tackle the societal problems of mobility, most policymakers at various levels (local, national, and European) agree that it would be desirable to reduce the role of the car. Across Europe, many attempts have been made to stimulate this over the past decades. However, with a few exceptions, the results have been very meagre. One result of this is that policymakers as well as other actors in the field have become increasingly skeptical about the possibilities of changing people's travel habits. In the Netherlands, for instance, an advisory council on mobility recommended, in late 1999, that attempts to make life difficult for car users should be stopped (v rom Council 1999).

Indeed, looking at traffic and transport at the regime level, the position of the car seems unchallenged. The number of cars as well as the amount of vehicle-kilometers travelled have risen continuously throughout the 2oth century. It is a paradigmatic example of how regimes tend to perpetuate themselves by incremental change, leaving some basic features uncontested.

The impossibility of changing people's travel behaviour is further supported by stated preference surveys, the most widely used instrument to scan people's transportation needs and to assess the potential of possible innovations. Such surveys, however, give a poor indication of the potential for change, as people tend to think in terms of their current needs and behaviour and the technologies they are familiar with.

What current approaches actually do is neglect the societal/behavioural side of innovation processes. By taking people's unwillingness to change their travel behaviour as a starting point, they subsequently turn this into a selffulfilling prophecy by stimulating those alternatives that require little or no change of behaviour. Options that do require a change of behaviour are dismissed because they are considered unrealistic. This assumption is not only questionable, it also bypasses the greatest potential to tackle transportation problems.

The assumption is debatable because "hands-on" experience in experiments (in contrast to survey questionnaires) indicates that users are willing to change their behaviour even contrary to their own expectations. On the basis of the three cases described in this chapter, we illustrated that Evs, which are usually discarded because they are "technically inferior", can also be a source of innovation on the behavioural side.

With this experience, and given the magnitude of the problems encountered and the likelihood that they will worsen in view of the expected mobility growth, it is neither justified nor wise to take car dominance as an unquestioned starting point. Unsuccessful attempts to change people's travel habits 
in the past should not be taken as an example of the impossibility to achieve this but, rather, as an opportunity to learn something about how regimes may or may not change. Past attempts sought to tackle the car-dominated traffic and transport regime head-on, attempting to stimulate the "common user" to change his or her travel habits. It is acknowledged that people in smaller niches behave differently, but these are not seen as representative of the common user. Therefore, these niches are taken to be of little relevance to the issue of tackling the problems of traffic and transport. As a result of this attitude, there have been numerous experiments with traffic and transport innovations which have been accepted as failures, and the reports on which have vanished deep down into a drawer never to reappear.

However, the scrap heap of failed experiments is probably also a goldmine of relevant lessons, especially if we pay attention to the socio-technical nature of innovation. That these experiences are only based on small experiments should not be an argument in favour of the idea that they are invalid for larger groups. In the history of socio-technical change, there are many examples of regime transformations where the initial users were not representative of the later "common" user. The history of the personal computer is a clear case in point. The challenge is to try and understand, partly via learning in follow-up socio-technical experiments, how further developments can make the innovation attractive to larger groups of users.

Taking behavioural change serious in an experimental setting may smooth the path via which an alternative option can be used on a larger scale. This broadens the range of options to solve problems, compared to the myopic focus on technical aspects that is largely current practice. For instance, it is often argued that battery capacity is a large barrier to the widespread use of Evs. This depends, however, on what type of $\mathrm{EV}$ is used for what type of purpose. For instance, in a follow-up to the Praxitèle experiment, it might appear that the ideal vehicle is a small, lightweight two-seater $\mathrm{Ev}$ that has a typical range of $50 \mathrm{~km}$ a day. Because it is lightweight, it is very energy efficient, and because it is typically operated at moderate speeds, the range might be realised with a $100-\mathrm{kg}$ battery with a minor back-up facility to recharge (partly) some of the vehicles during daytime. This contrasts with the expensive 500-kg battery that is common in current $\mathrm{Ev}$ s, thus largely dispelling the battery problem. ${ }^{11}$

The big issue, of course, is how such learning can be used to make the traffic and transport regime (more) sustainable. On this issue, we need to be modest, partly since past experiments and the way they have been evaluated have only hinted at the potential for a regime transformation rather than demonstrating it. On the basis of the cases presented in this chapter, we cannot conclude that these EV systems in their current form should be a central 
element of a sustainable traffic and transport system. The knowledge base to decide this upon is still far too small.

Another reason to be modest is that sTs research, in particular, has demonstrated that socio-technical change is a very complicated process in which large numbers of actors and factors play a role. This makes it very difficult or even impossible to guide or steer these processes towards achieving societal goals. Maybe the best we could strive for is to "modulate" the ongoing dynamics (Rip and Schot 2002). Still, however difficult this may be, new socio-technical configurations that have been demonstrated in a niche have a better chance of "breaking through" than options that have been dismissed a priori. For that reason, the approach of Strategic Niche Management is important to broaden the range of new socio-technical configurations that work, i.e., work technically as well as socially.

In that sense, the cases do allow an important conclusion, namely, that users are willing to, and certainly do, change their behaviour when they are confronted with specific new transport options in experiments. Stated preference surveys, in most cases the most important instrument to assess user requirements, are a poor indicator of this and can never match learning from experience. The challenge, therefore, is to design a sufficient range of experiments to be able to draw more general conclusions on what is possible under which conditions.

This then broadens the range of options that have been proven in practice and may point to a variety of promising options that are too easily dismissed in current transport policy. The way in which one can actually stimulate the implementation of the most sustainable options is a follow-up issue that is beyond the scope of this chapter, but by broadening the range of alternatives, the "socio-technical" strategy sketched above can definitely make an important contribution en route to a sustainable traffic and transport regime.

Innovation is a co-production process in which technical as well as social/behavioural aspects change. Mainstream approaches to tackling the current problems of transport, however, neglect this socio-technical nature. Behavioural change is considered unrealistic, and current transportation policies focus on technical solutions. Although, like any other innovation, this will also evoke some societal/behavioural changes, a lot of the potential falls by the wayside in a largely self-fulfilling approach.

This becomes most clearly visible in the small-scale experiments such as the ones described above. They point to potential new socio-technical configurations that could be important in a sustainable mobility regime. Taking these lessons seriously and, moreover, designing and evaluating experiments in such a way that behavioural change may be induced may reveal more solid stepping stones for a route towards sustainable mobility. 


\section{Notes}

1 The concept of a "technological niche" should not be confused with a "market niche". The latter refers to a subsection of a larger economic market with specific characteristics, like the market for advanced sports cars. These characteristics are taken more or less to fix the size of that market. In contrast, a technological niche initially needs "outside protection" to survive. After a period of development and learning, however, the protection needs to be removed, after which market expansion becomes one of the main targets. Thus, a technological niche represents a specific phase in an innovation process, preceding market development, whereas a market niche represents a specific type of market. Cf. Elzen et al. (1999).

2 Not all vehicles need to be zevs. Hybrid cars (that combine an internal combustion engine with an electric drive) that can drive a certain distance on their battery may be counted as "partial zevs".

3 u to P a - Urban Transport: Options for Propulsion Systems and Instruments for Analysis. Further info can be found on the Internet: http://www.utopia-eu.com/

4 Largely based on Harms and Truffer (1998), and Schwegler and Trento (2000). Additional information can be found on the Internet: http://www.infovel.ch/

5 Largely based on Simon (1998), Bleijs et al. (1998), and Carli (2000).

6 Largely based on Carrara and Inaudi $(1997,1998)$ and Zwaneveld et al. (2000).

7 Various other experiments also indicate that at least certain groups of users are open to new travel options, such as the Autoplus/Liselec experiment and the Touc in France, and the ASTI minibus in the U K.

8 This is evident from a variety of projects the author has recently been engaged in, such as INTEP OL (cf. Elzen et al. 2001), UTOPIA (cf. www.utopia-eu.com), SNM project (cf. Weber et al. 1999; Hoogma et al. 2001).

9 The author is currently engaged in research to develop this kind of evaluation requirements for various types of options from the "portfolio of promises".

10 The most widely used concept in this respect is "governance" (for an overview, see Kersbergen and Van Waarden 2001). The author and his colleagues have contributed, using the concept of "Interactive Technology Policy" (Elzen et al. 2001).

11 Experience with the Touc in Toulouse underscores this point. Here, an Ev is used to transport people between their homes and a supermarket, in a service provided by the Casino supermarket chain. The organisers prioritised the service they wanted to provide to specific customers, and subsequently chose the simplest EV technology to satisfy this need. The technical solution chosen was unconventional, a modified golfcart, but it did what it had to do in order to serve the needs of customers. It is considered such a success that it will be used in various other French cities in the near future as well (Guellard 2000). 